The publication included in this document should be referenced as follows:

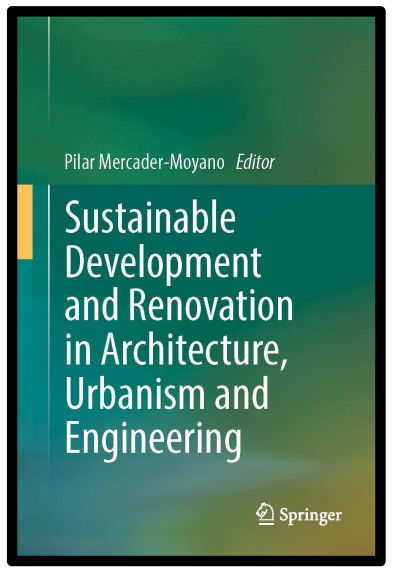

\title{
MARCH 2017 \\ Update of the Urban Heat Island of Madrid and Its Influence on the Building's Energy Simulation
}

Miguel Núñez Peiró, Carmen Sánchez-Guevara Sánchez \& Francisco Javier Neila González

included in:

Sustainable Development and Renovation in Architecture, Urbanism and Engineering

Publication details, including instructions for authors and subscription information: https://link.springer.com/book/10.1007/978-3-319-51442-0

Please cite this document as:

Núñez Peiró, M., Sánchez-Guevara Sánchez, C., \& Neila González, F.J. (2017). Update of the Urban Heat Island of Madrid and Its Influence on the Building's Energy Simulation. In P. Mercader-Moyano (Ed.), Sustainable Development and Renovation in Architecture, Urbanism and Engineering (pp. 339-350). Springer International Publising.

DOI: 10.1007/978-3-319-51442-0_28

To link to this document:

https://link.springer.com/chapter/10.1007/978-3-319-51442-0 28

The following document has been archived according to the publisher's default policies as a PRE-PRINT versión on the repository of the Universidad Politécnica de Madrid.

For more information, please visit:

http://www.sherpa.ac.uk/romeo/index.php?la=en\&fIDnum=|\&mode=simple

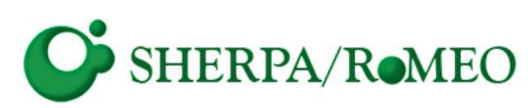




\title{
Update of the urban heat island of Madrid and its influence on the building's energy simulation
}

\author{
Núñez Peiró, Miguel ${ }^{(1, *)}$, Sánchez-Guevara Sánchez, Carmen ${ }^{(1)}$, Neila \\ González, F. Javier ${ }^{(1)}$
}

(1) ABIO Research Group. Universidad Politécnica de Madrid.

(*) miguel.nunez@upm.es, +34 913363889

\begin{abstract}
Despite great advances on building energy evaluation, available climate data does not include the effects of the Urban Heat Island (UHI). This phenomenon, which increases the temperature in urban areas, is variable in both time and space, and implies an important lack of accuracy when simulating within an urban context. During this research the relevance of the UHI in relation to the dwellings energy performance has been confirmed, as well as the existing barriers to integrate the current UHI representations into the dynamic energy simulation process. Therefore, it is necessary to carry out an update of the existing models, in order to implement it into the energy evaluation process. In this work, as a first stage of the study and based on current techniques of geolocation and the use of Geographic Information Systems (GIS), it is established a methodology to acquire automatically an update of the UHI through isotherm maps. It is aimed to set up the starting point from which the integration of the UHI into the energy simulation process will happen.
\end{abstract}

Keywords Urban Heat Island; climate; update; Madrid; energy simulation

\section{Introduction}

Nowadays building energy evaluation tools play a key role in stablishing the basic energy strategies in the building sector. They do not only help to improve the decision-making about building design and its inhabitants' comfort, but also to stablish the payback periods and select the best solution among all the possibilities in both new and renovated buildings.

Despite the last decades have witnessed great advances in building evaluation, there are still some disagreement between the simulation results and reality (Coakley et al., 2014). Several studies have addressed the issue, focusing on the models' calibration through the improvement of the thermodynamic algorithms, the user interaction profiles and the weather conditions (Evins, 2013; Foucquier et al., 2013; Fumo, 2014).

The Urban Heat Island (UHI) relates to the last one, and it consists in the temperature differences between the built (urban) and the unbuilt landscape (rural). Regardless the wide knowledge about the UHI, available climate data does 
not include its effects, as they undertake the regional scale. Previous studies in this research project have already anticipated the relevance of this phenomenon in the building energy evaluation (López Moreno et al., 2015), and so the significance of addressing the integration of the UHI effects in the buildings' energy simulations.

\section{Background}

Due to the sum of factors that influence the UHI formation, as well as its temporal and spatial variation, having an in-depth record of the phenomenon requires a large amount of measurements. While the first studies focused on detecting the existence of the UHI and identifying those areas with the greatest intensity (Arnfield, 2003; Santamouris, 2007, 2015), in recent years much of the research efforts have been linked to the development of numerical models, which allow to study the urban heat island dynamically (Mirzaei, 2010).

The first UHI study in Spain was carried out in the city of Madrid (López Gómez et al., 1988, 1993), where the transects methodology ${ }^{1}$ was used. It was followed by many other works related to specific questions of urban climate (Almendros et al., 1995; Fernández García, 2001; Sobrino et al., 2009), and even a numerical model that tried to explain the urban heat island's behaviour at both the mesoclimatic and microclimatic scale. (Salamanca et al., 2010, 2011).

These studies, however, have not proven to be consistent with the objective of this research, given its age, their inability to generate hourly records, and their lack of accuracy at the microclimatic scale (Grimmond et al., 2010, 2011). Based on the recommendations that point towards the development of models built upon the target of the research (Mirzaei et al., 2015), this project aims to generate an empirical model from the collected data at multiple fixed urban locations (Kolokotroni et al., 2006, 2010; Mihalakakou et al., 2002).

This paper addresses the first phase of the development of the model, carrying out an update of the last surveys in the spatial distribution of the UHI, which dates back to the late $1980 \mathrm{~s}$.

\section{Means and methods}

This research replicates the methodology used in the first study of Madrid's UHI (López Gómez et al., 1988), based on the development of proximity measurements through urban transects. In order to reckon the highest intensity of the urban heat island, the data gathering was performed under anticyclonic weather conditions with a cloudless sky, calm wind and few hours after the sunset (2100 - 2300 UTC). Three simultaneous transects configured a set of observations, conducting each of them twice on every set (return trip), and providing the temperature records used in the results section.

\footnotetext{
1 The transects methodology refers to transversal itineraries through the city, commonly carried out simultaneously, and from which the air temperature at multiple points is obtained.
} 
Needs to be mention that our study refines the process of planning, data gathering, and analysis. These improvements allowed for the reduction of the needed means, helped to automate the process, and to better the precision and the resolution of the results. In the next sections we explain its characteristics.

\subsection{Itineraries and geolocation}

Since the original itineraries from the study of 1988 are not suited to the current road hierarchy of the city, new routes were created for each transect based on the original measuring points. It has been necessary to generate a digital transport network, continuous along the entire city, and able to emulate the current traffic restrictions. For its development it was used the Network Analyst extension of ArcGis 10.3 as well as the Openstreetmap base map. Afterwards, the new routes were integrated into a mobile application to enable monitoring and geolocation at every single position of the vehicle.

\subsection{Equipment and data gathering}

Three temperature sensors and dataloggers were used for the temperature record. Each sensor consisted on a NTC (Negative Temperature Coefficient) exposed thermistor, with an accuracy of $\pm 0,2{ }^{\circ} \mathrm{C}$ and a response time of $t_{90}=60$ seconds (figure 1). Virtually immediate response was guaranteed for the sensor at speeds above $30 \mathrm{~km} / \mathrm{h}$, and thus enabling to detect temperature differences in up to 10 seconds' intervals.

The transects were carried out by car, with the sensor placed at the roof and distanced from the surface and the exhaust pipe. Since the measurements took place several hours after sunset, it was not necessary to protect the sensor from solar radiation.

Datalogger Testo 175 T2

Dimensions: $\quad 89 \times 53 \times 27 \mathrm{~mm}$

Channels: 2 (int/ext)

Measuring rate: $10 \mathrm{~s}-24 \mathrm{~h}$

Measuring range: $-35 \ldots+55^{\circ} \mathrm{C}$

Accuracy: $\quad \pm 0,5^{\circ} \mathrm{C}$

\section{Sensor NTC exposed thermistor}

Dimensions: $\quad \varnothing 5 \times 115 \mathrm{~mm}$

Measuring range: $\quad-50 \ldots+125^{\circ} \mathrm{C}$

Accuracy: $\quad \pm 0,2^{\circ} \mathrm{C}$

Response time: $\quad t_{90}=60 \mathrm{~s}$
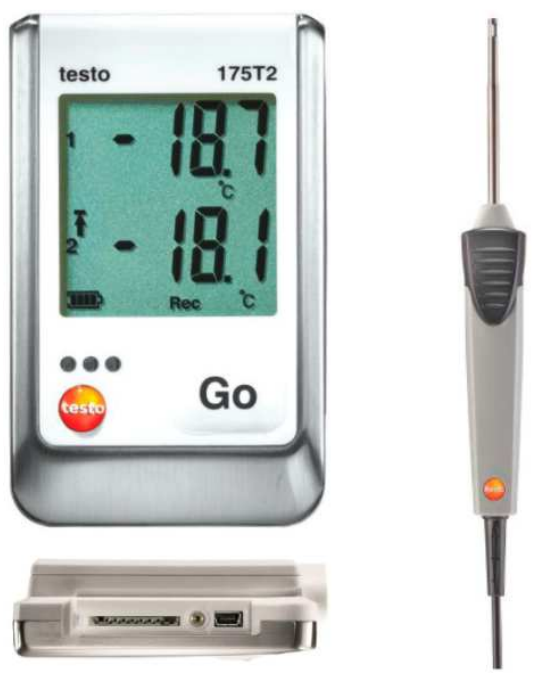

Fig. 1 Technical data of the equipment used in the measurements. Source: Testo AG. 


\subsection{Analysis tools, interpolation techniques and maps generation}

On the basis of the obtained data, a frequency distribution analysis of each data set was carried out in order to identify common patterns among them.

Also several isotherm maps were created for each set of observations. For that process a geostatistical analysis method called cokriging was used. The kriging is a technique that allows, by interpolating a particular batch of data, to predict the value on a given point:

$$
\hat{Z}\left(s_{0}\right)=\sum_{\mathrm{i}=1}^{n} \lambda_{\mathrm{i}} Z\left(s_{\mathrm{i}}\right)
$$

The variogram, which is the function that describes the spatial correlation in the kriging, was set to be exponential (2), as it has been widely used in meteorology and contamination prediction (Palomino et al., 2015).

$$
\gamma(h)=c_{0}+c\left(1-\exp \left(\frac{-h}{r}\right)\right) ; \quad h>0
$$

Previous research have also pointed out that the stream beds influence the UHI distribution (Fernández García et al., 1996). Therefore, the model was completed with a DTM layer (Digital Terrain Model) in order to provide information on the altimetry. All the process was fulfilled with the Geostatistical Analyst package from ArcGIS 10.3.

In addition to the 101 points from the transects, collected data from six observatories of the National Meteorological Agency (AEMET) and from nine urban stations of the air quality system (SICAM) were added to the process, giving a total of 116 measuring locations (figure 2).

- Transect's measuring point

- AEMET observatories

- Air quality stations

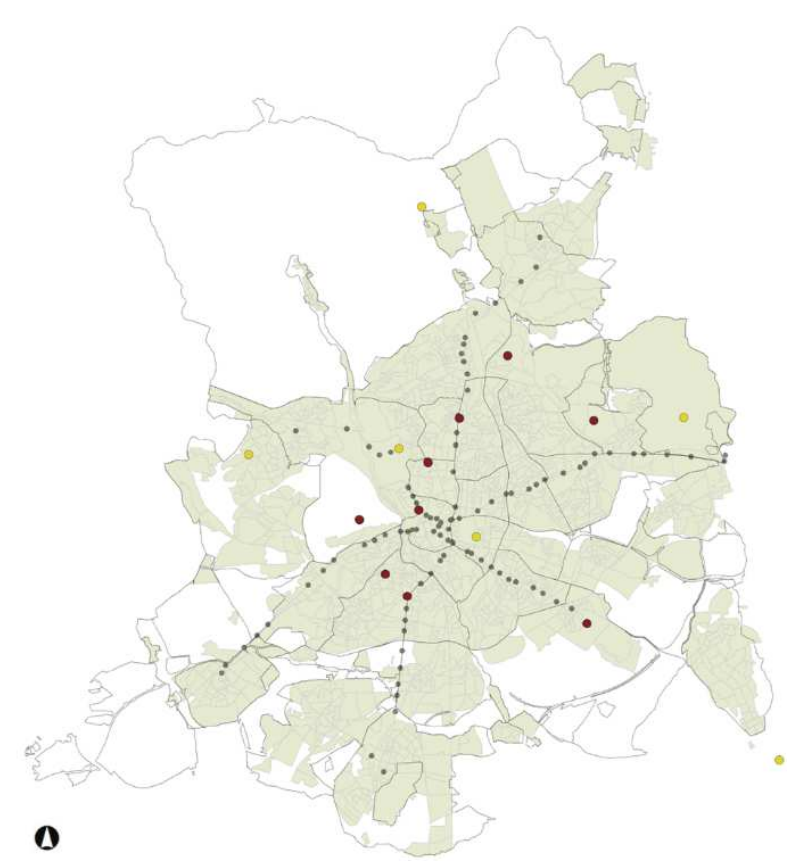

Fig 2. Location of the observation points used in the map's generation. 


\section{Results \& discussion}

Four data sets were obtained from the measurements that were carried out between July 2015 and April 2016. Each data set corresponds to one season, as the measurements took place around one month after the solstices and equinoxes. As it is explained in 3 Means and Methods, all measurements were performed under the same atmospheric conditions, at the same time and following the identical itineraries.

Table 1 shows a summary of the most important statistical parameters that were used during the analysis of the frequency distribution and the isotherm maps' generation.

Table 1 Statistical parameters from each temperature data set

\begin{tabular}{l|c|c|c|c}
\hline Parameter & July $\mathbf{1 5}^{\text {th }} \mathbf{2 0 1 5}$ & October $\mathbf{2 8}^{\text {th }}, \mathbf{2 0 1 5}$ & February $\mathbf{1 6}^{\text {th }} \mathbf{2 0 1 6}$ & April 25 $\mathbf{2 0 1 6}^{\text {th } \mathbf{2 0}}$ \\
\hline Average & 31,2 & 12,8 & 2,6 & 15,6 \\
\hline Minimum & 27,3 & 11,2 & $-0,6$ & 12,1 \\
\hline $\mathbf{P}_{\mathbf{1 0}}$ & 28,7 & 11,9 & 1,5 & 13,7 \\
\hline $\mathbf{P}_{\mathbf{5 0}}$ & 31,6 & 12,9 & 2,6 & 15,6 \\
\hline $\mathbf{P}_{\mathbf{9 0}}$ & 33,1 & 13,4 & 3,8 & 17,4 \\
\hline $\begin{array}{l}\text { Maximum } \\
\text { Range }\end{array}$ & 33,7 & 13,8 & 5,9 & 18,0 \\
\hline $\begin{array}{l}\text { Standard } \\
\text { deviation }\end{array}$ & 1,6 & 2,6 & 6,5 & 1,3 \\
\hline
\end{tabular}

\subsection{Frequency distributions}

The analysis of the frequency distribution (figure 3) shows that it can be inferred the intensity of the urban heat island from the data dispersion of each data set. Thus, it can be observed a decreasing pattern on the UHI intensity from summer to winter $(a-b-c)$ and backwards $(c-d-a)$, in line with the results of previous research (Núñez Peiró et al., 2016). 
While confirming that the greater UHI intensity happens in the warmest month, the differences between the measurements from autumn $(b)$ and spring $(d)$ are remarkable, since both were performed at times of the year in which historical temperature records are very similar $\left(\operatorname{Tmax}=16-20^{\circ} \mathrm{C} ; \mathrm{Tmin}=6-7^{\circ} \mathrm{C}\right)$.

This can be explained by the fact that, at this latitude, the UHI intensity seems to have a high dependence upon solar radiation. It is noted, therefore, that the urban heat island does not have a symmetrical behavior regarding the seasons but in relation to the solstices, intensifying or softening its effect depending on the proximity to them.

Consequently, the measurements could be presented from the highest to the lowest intensity: the data set $a$ distances itself 24 days from the solstice, the $d$ does 57 days, the $c$ does 125 days and the $b$ does 129 days. Moreover, it can be explained the resemblance between the autumn $(b)$ and the winter $(c)$ measurements, located symmetrically from the solstice and under the same solar radiation.
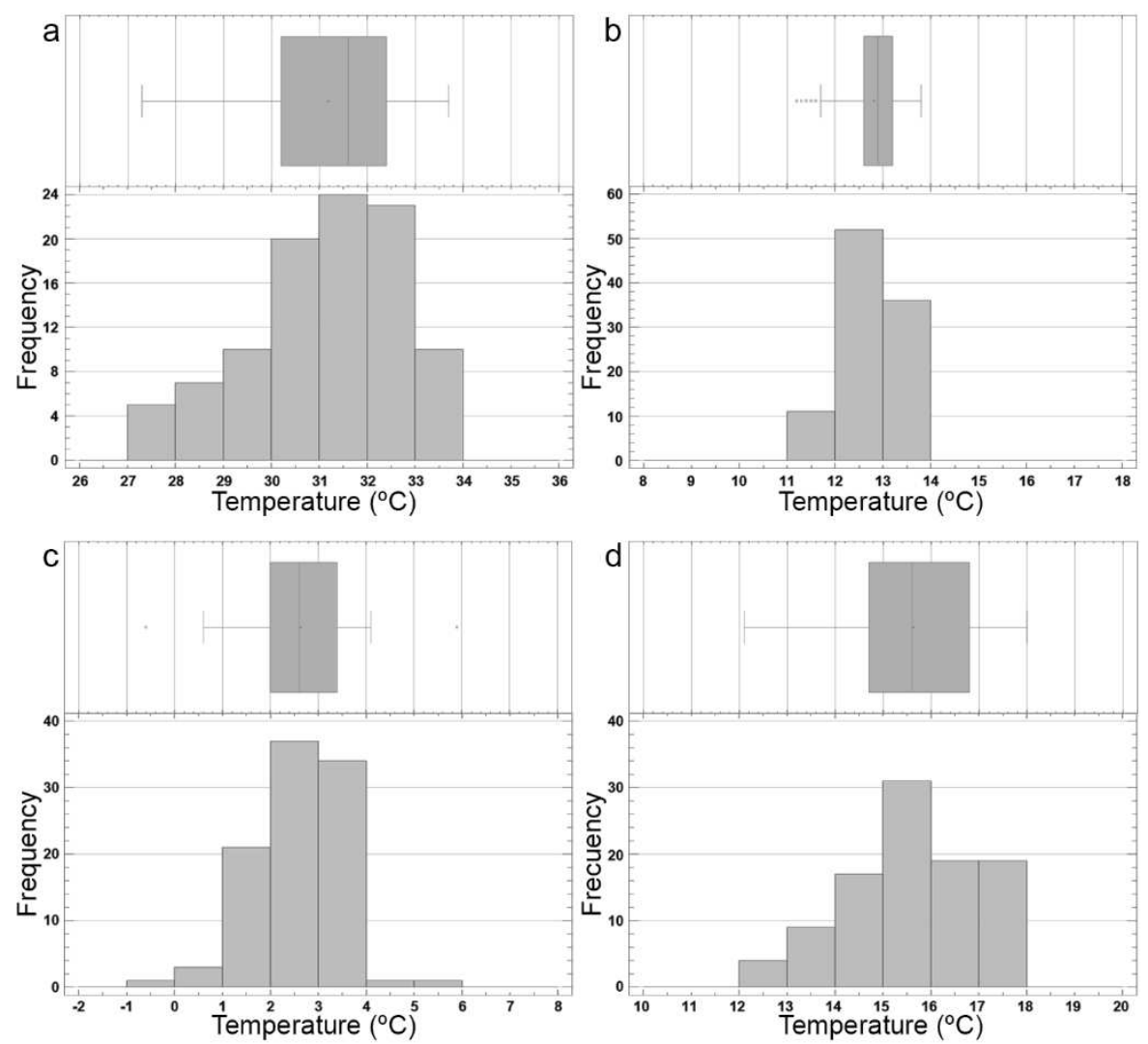

Fig. 3 Frequency distribution of temperature for each data set, presented in chronological order. $a$ : July $15^{\text {th }}, 2015 ; b$ : October $28^{\text {th }}, 2015 ; c$ : February $16^{\text {th }}, 2016 ; d$ : April $25^{\text {th }}, 2016$. 


\subsection{Isotherm maps}
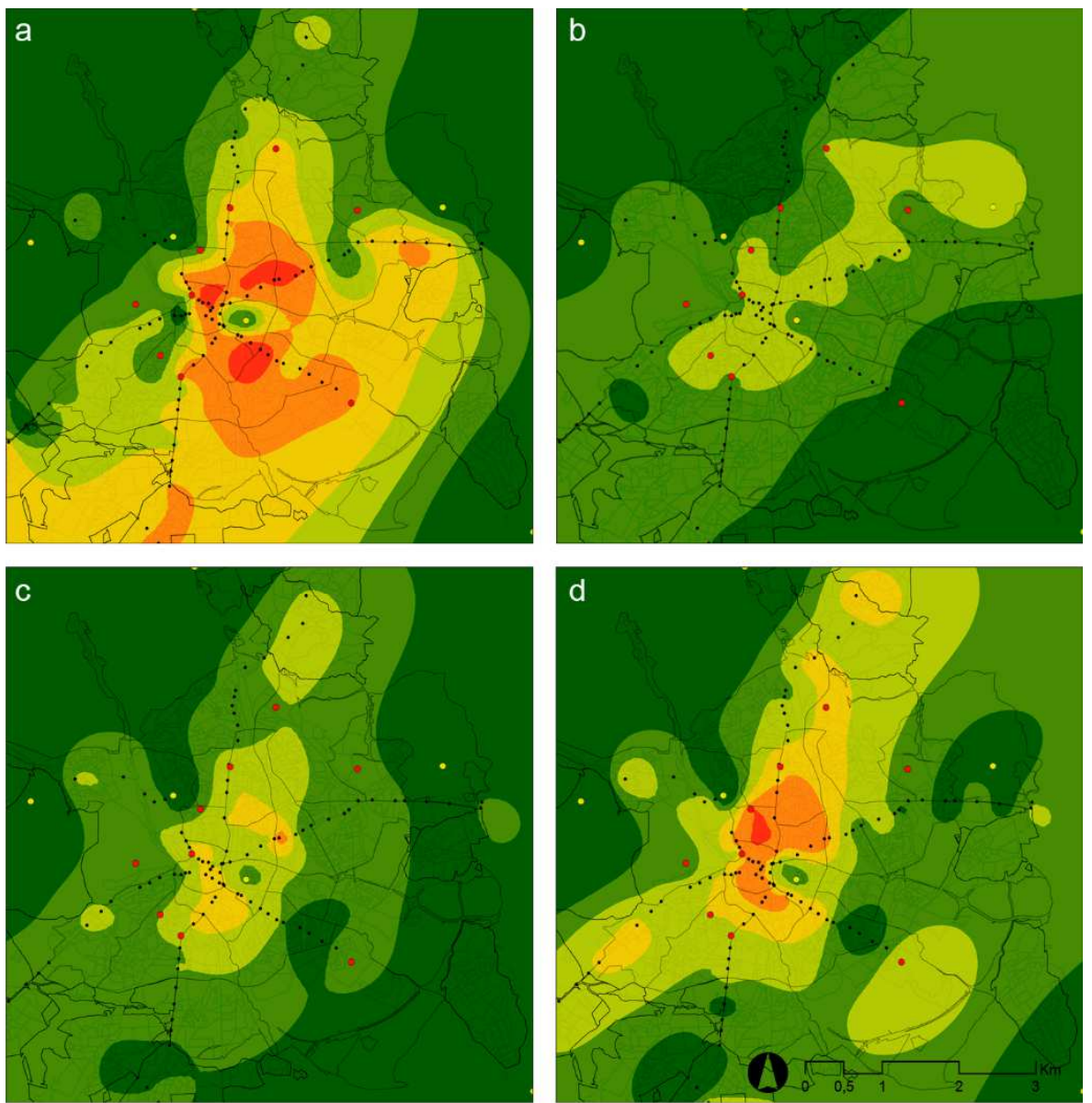

- Air quality stations

- AEMET observatories

- Transect's measuring point

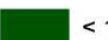

$<1$

$1-2$

$2-3$

$3-4$

$4-5$

$>5$

Fig. 4 Isotherm maps based on temperature variation for each data set, presented in chronological order. $a$ : July $15^{\text {th }}, 2015 ; b$ : October $28^{\text {th }}, 2015 ; c$ : February $16^{\text {th }}, 2016 ; d$ : April $25^{\text {th }}, 2016$.

Based on the temperature records collected during the measurements, and by following the methodology described in section 3.3 Analysis tools, interpolation techniques and maps generation, there have been generated different maps of isotherms for each season (figure 4). These maps represent the temperature difference between each observation point and a reference value.

Usually the reference value is taken from a rural location placed in the surrounding of the city. It should be said that it is not an easy task to locate it, as there are consistent doubts about what can be considered a rural location, or how to ensure that the measurement of that particular point is truly representative of the surroundings of the city. Those doubts have led, among other things, to question 
the methodology and results from hundreds of UHI studies developed around the world (Stewart, 2011).

Another approach to determine the reference temperature value consists, when developing urban transects, in taking the minimum temperature of the series. However, as it can be seen in figure 4.c, there are cases where the minimum temperature corresponds to an atypical value. Although this does not mean that measurements are necessarily erroneous, using them as a reference value when generating a map could cause huge distortions and come to wrong conclusions. It should also be noted that in this study the coldest record was never found at the same location, moving from Ciudad Universitaria at the west (summer) to the exit of Madrid at the north (autumn), to the vicinity of the Jarama river at the east (winter) and to the entrance of Getafe in the south (spring).

This study, instead of setting a temperature value for the coldest point, it poses the use of the first decile of the data set as a reference value for the first isotherm. It was found that this process downplays the weight of any atypical and leads to a better and easier comparison between different maps of isotherms.

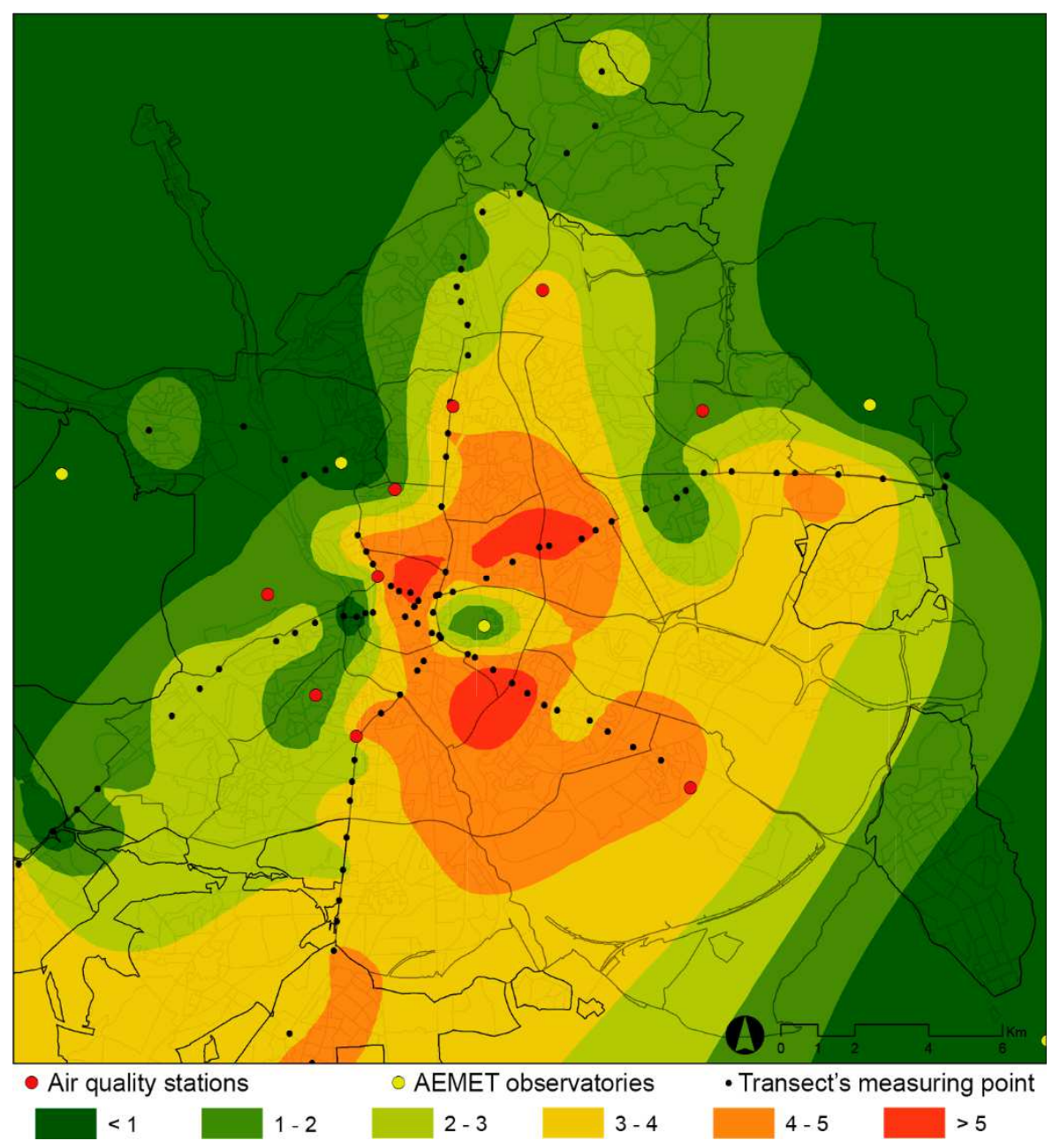

Fig. 5 Isotherm map based on temperature variation at midnight. July $15^{\text {th }}, 2015$. 
Figure 5 shows in more detail the spatial distribution of the UHI at its greatest intensity (July $\left.15^{\text {th }}, 2015\right)$. This has been compared with another isotherm map from the same time of the year, but using data from 30 years ago (July $11^{\text {th }}, 1985$; figure 6). The temperatures were obtained from the temperature profiles published in the first UHI study of Madrid (López Gómez et al., 1988).

It is observed that the morphology of both of them is very similar. The concentric distribution of the urban heat island is tinged with a more intense development in the NE-SW axis, in line with the urbanization expansion. It is found a repeated pattern in Ciudad Universitaria, as it is in both cases the closest point to the city with the lowest temperature. The surroundings of the park $E l$ Retiro, with a cool island, show a similar behaviour too. Results confirm that the villages around the city of Madrid are under the effect of micro-heat islands, with an intensity of one to three degrees Celsius. Confirming that there are some urban fabrics that cause either a rise or a fall in temperatures is worth of interest as well.

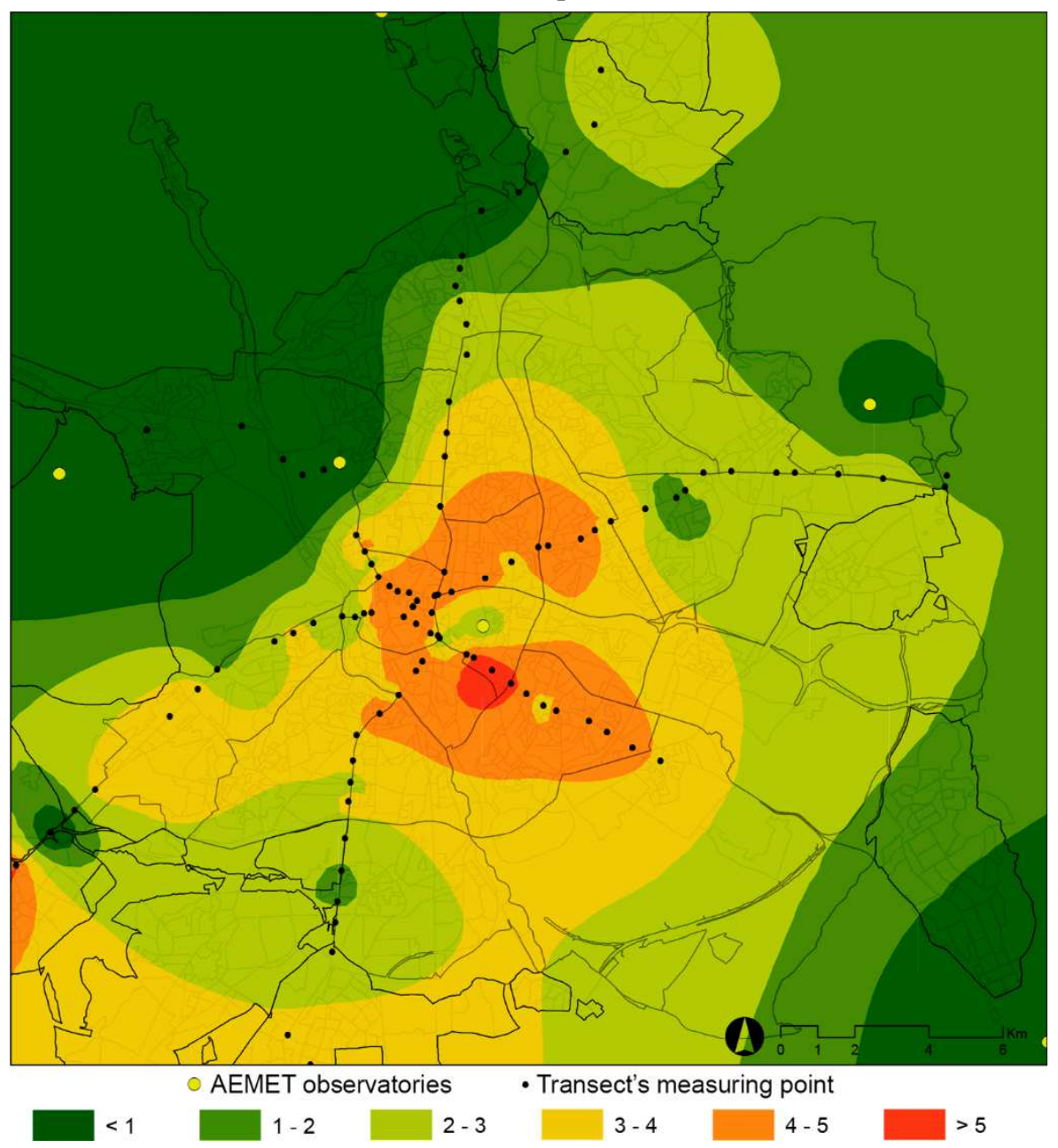

Fig. 6 Isotherm map based on temperature variation at midnight. July $11^{\text {th }}$, 1985. After López Gómez et al. (1988) 
Regarding the evolution of the urban heat island during the last 30 years, it seems clear that the UHI has enlarged its size and increased the number of urban areas that bear the hottest temperature records (those where the intensity is over $4^{\circ} \mathrm{C}$ ). However, the UHI intensity does not seem to be increasing itself, as the maximum values are in both cases around $5-6^{\circ} \mathrm{C}$.

It appears that the growth of the city has effectively increased the domain of the urban heat island, spreading its higher effect over new areas. However, it does not seem enough to increase its intensity at the points where already had reached the maximum, probably because the urban fabric is consolidated and has changed little or nothing over the last three decades.

\section{Conclusions}

This research confirms that the urban heat island of Madrid has grown from the study that was firstly developed between 1984 and 1986 (López Gómez et al., 1988). It has been observed an increase in its area of influence, in particular on those parts with the highest temperatures.

Despite the significant human effort and the material means that were needed, the methodology that was used to carry out this updating of the UHI has turned out to be extremely useful. Due to the improvements that were implemented on the process, we expect to perform an urban climate analysis on a lower scale.

The comparison of the data sets from different times of the year suggests that the highest intensity happens around the summer solstice, mainly due to the greater amount of solar radiation that is received and accumulated by the urban fabric. Contrary to what is said in the study from 1988, the intensity of the UHI appears to reach its minimum around the winter solstice. The differences between both studies seems to be on the rural reference value.

In conclusion, the findings of this study have provided an updated base for the decision-making of UHI related aspects. These results could be used in many fields related to the urban climate, and it stands as an essential tool to select the most relevant locations of the urban microclimate. Ultimately, it completes the first stage of the dynamic model that will integrate the UHI effects into the building energy evaluation.

\section{Acknowledgements}

This research is funded by Programa de I $+D+I$ orientada a los retos de la sociedad 'Retos Investigación' of the Ministry of Economy and Competitiveness. Grant code BIA2013-41732-R, MODIFICA Project: Predictive Model For Dwellings Energy Performance Under The Urban Heat Island Effect.

Authors would also like to thank the State Meteorological Agency (AEMET) and Madrid Air Quality Integral System for weather data provided to carry out this research. 


\section{References}

Almendros, M. Á., \& López Gómez, A. (1995). La isla de calor en Madrid y las situaciones sinópticas. Estudios Geográficos, 56(219), 207-221.

Arnfield, a. J. (2003). Two decades of urban climate research: A review of turbulence, exchanges of energy and water, and the urban heat island. International Journal of Climatology, 23(1), 1-26.

Coakley, D., Raftery, P., \& Keane, M. (2014). A review of methods to match building energy simulation models to measured data. Renewable and Sustainable Energy Reviews, 37, 123-141.

Evins, R. (2013). A review of computational optimisation methods applied to sustainable building design. Renewable and Sustainable Energy Reviews, 22, 230-245.

Fernández García, F. (2001). El clima urbano de Madrid y su influencia sobre el confort térmico. Boletín de La Real Sociedad Geográfica, 137-138, 12.

Fernández García, F., Almendros Coca, M. Á., \& López Gómez, A. (1996). La influencia del relieve en la isla de calor de Madrid: las vaguadas del Manzanares y del Abroñigal. Estudios Geográficos, 57(224), 473-494.

Foucquier, A., Robert, S., Suard, F., Stéphan, L., \& Jay, A. (2013). State of the art in building modelling and energy performances prediction: A review. Renewable and Sustainable Energy Reviews, 23, 272-288.

Fumo, N. (2014). A review on the basics of building energy estimation. Renewable and Sustainable Energy Reviews, 31, 53-60.

Grimmond, C. S. B., Blackett, M., Best, M. J., Baik, J.-J., Belcher, S. E., Beringer, J., ... Zhang, N. (2011). Initial results from Phase 2 of the international urban energy balance model comparison. International Journal of Climatology, 31(2), 244-272.

Grimmond, C. S. B., Blackett, M., Best, M. J., Barlow, J., Baik, J.-J., Belcher, S. E., ... Zhang, N. (2010). The International Urban Energy Balance Models Comparison Project: First Results from Phase 1. Journal of Applied Meteorology and Climatology, 49(6), 1268-1292.

Kolokotroni, M., Davies, M., Croxford, B., Bhuiyan, S., \& Mavrogianni, A. (2010). A validated methodology for the prediction of heating and cooling energy demand for buildings within the Urban Heat Island: Case-study of London. Solar Energy, 84(12), 2246-2255.

Kolokotroni, M., Giannitsaris, I., \& Watkins, R. (2006). The effect of the London urban heat island on building summer cooling demand and night ventilation strategies. Solar Energy, 80(4), 383392.

López Gómez, A., López Gómez, J., Fernández García, F., \& Arroyo Ilera, F. (1988). El Clima urbano de Madrid: La isla de calor. Madrid: CSIC. 
López Gómez, A., López Gómez, J., Fernández García, F., \& Moreno Jiménez, A. (1993). El Clima urbano: teledetección de la isla de calor en Madrid. Madrid: MOPT.

López Moreno, H., Sánchez-Guevara Sánchez, C., Román López, E., \& Neila González, F. J. (2015). Thermal characterization of urban heat island according to urban morphology of Madrid. In Proceedings of the III International Congress on Construction and Building Research.

Mihalakakou, G., Flocas, H. a., Santamouris, M., \& Helmis, C. G. (2002). Application of Neural Networks to the Simulation of the Heat Island over Athens, Greece, Using Synoptic Types as a Predictor. Journal of Applied Meteorology, 41(5), 519-527.

Mirzaei, P. A., \& Haghighat, F. (2010). Approaches to study Urban Heat Island - Abilities and limitations. Building and Environment, 45(10), 2192-2201.

Mirzaei, P. A., Olsthoorn, D., Torjan, M., \& Haghighat, F. (2015). Urban neighborhood characteristics influence on a building indoor environment. Sustainable Cities and Society, 19, 403-413.

Núñez Peiró, M., Román López, E., Sánchez-Guevara Sánchez, C., \& Neila González, F. J. (2016). Hacia un modelo dinámico para la isla de calor urbana de Madrid = Towards a Dynamic Model for the Urban Heat Island of Madrid. Anales de Edificación, 2(1), 49-58.

Palomino, I., Vivanco, M. G., Theobald, M., Garrido, J. L., \& Martín, F. (2015). Evaluación de la calidad del aire en España utilizando modelización combinada con mediciones. Preevaluación 2014. Madrid.

Salamanca, F., \& Martilli, A. (2010). A new Building Energy Model coupled with an Urban Canopy Parameterization for urban climate simulations-part II. Validation with one dimension off-line simulations. Theoretical and Applied Climatology, 99(3-4), 345-356.

Salamanca, F., Martilli, A., \& Yagüe, C. (2011). A numerical study of the Urban Heat Island over Madrid during the DESIREX (2008) campaign with WRF and an evaluation of simple mitigation strategies. International Journal of Climatology, 32(15), 2372-2386.

Santamouris, M. (2007). Heat Island Research in Europe: The State of the Art. Advances in Building Energy Research, 1(1), 123-150.

Santamouris, M. (2015). Analyzing the heat island magnitude and characteristics in one hundred Asian and Australian cities and regions. Science of The Total Environment, 512-513, 582-598.

Sobrino, J. a, Sòria, G., Romaguera, M., \& Cuenca, J. (2009). Desirex 2008 : Estudio de la isla de calor en la Ciudad de Madrid. Revista de Teledetección, 31, 80-92.

Stewart, I. D. (2011). A systematic review and scientific critique of methodology in modern urban heat island literature. International Journal of Climatology, 31(2), 200-217. 